\title{
Screening in Women with Increased Breast Cancer Risk
}

\author{
Almut Artmann Karin Hellerhoff Sylvia H. Heywang-Köbrunner \\ Abteilung für Bildgebende und Interventionelle Mammadiagnostik, Klinikum rechts der Isar, TU München, Germany
}

\section{Key Words}

Breast cancer risk, familial - Breast cancer, hereditary .

Screening · Mammography · Ultrasound · Magnetic resonance imaging $\cdot \mathrm{MRI}$

\section{Summary}

About $10 \%$ of all breast cancer cases occur on a hereditary basis. BRCA1/2 (breast cancer oncogenes) account for about $50 \%$ of all hereditary breast cancer cases. The remaining cases of suspected inherited origin given by family histories might be associated with other known or currently unknown genes. Deleterious mutations in the BRCA1 or BRCA2 genes are associated with an increased life-time risk of breast and ovarian cancer. BRCA1/2 carriers are more likely in to develop breast cancer at a young age compared with the general population. For women at high breast cancer risk with a mean age under 40 years at diagnosis reported sensitivities of mammography and ultrasound are low, ranging around 30-40\%. Using magnetic resonance imaging (MRI) as a complementary imaging tool the sensitivity may increase to $90 \%$. However, the specificity of MRI appears to be generally lower than that of mammography and ultrasound. The data differ depending on patient selection and study design. However, all studies indicate that contrast enhanced magnetic resonance imaging may be the most promising method. Further investigations are still needed to minimize the false-postive rate and to investigate the efficacy of MRI as an integral screening modalitiy in the surveillance of women with increased breast cancer susceptibility.

\author{
Schlüsselwörter \\ Brustkrebsrisiko, familiäres · Brustkrebs, erblich . \\ Früherkennung · Mammographie · Ultraschall . \\ Kernspintomographie · MRT
}

\section{Zusammenfassung}

Etwa $10 \%$ aller Brustkrebsneuerkrankungen sind genetischer Genese. Die beiden Brustkrebsonkogene BRCA1 und BRCA 2 verursachen ca. 50\% aller erblichen Brustkrebserkrankungen. In den verbleibenden Fällen kann die familiäre Brustkrebserkrankung durch weitere Gene, die mitunter mit den zur Zeit verfügbaren Testmethoden noch nicht erfasst wurden, bedingt sein. Mutationen in beiden Genen sind mit einem erhöhten Lebenszeitrisiko für eine Erkrankung sowohl am Mamma- als auch am Ovarialkarzinom assoziiert. BRCA1/2-Trägerinnen erkranken häufig in deutlich jüngerem Alter als die Normalbevölkerung. In diesen Hochrisikokollektiven mit einem mittleren Erkrankungsalter unter dem 40. Lebensjahr ist die Sensitivität von Mammographie (30-40\%) und Sonographie (33\%) niedrig. Durch die zusätzliche Anwendung der Kernspintomographie (Magnetresonanztomographie, MRT) wird eine deutliche Erhöhung der Sensitivität auf bis zu ca. $90 \%$ erreicht. Die Spezifität der MRT ist geringer als die von Mammographie und Ultraschall. Angaben variieren jedoch in Abhängigkeit von der Präselektion der Patientinnen und dem Studiendesign. Die Kernspintomographie ist die meistversprechende Methode. Weitere Studien sind erforderlich zur Minimierung der Falsch-positiv-Rate und zur Einschätzung der prognostischen Relevanz.

\begin{tabular}{ll}
\hline KARGER & @ 2006 S. Karger GmbH, Freiburg \\
$\begin{array}{l}\text { Fax +49761 } 4520714 \\
\begin{array}{l}\text { E-mail Information@Karger.de } \\
\text { www.karger.com }\end{array}\end{array}$ & Accessible online at: \\
www.karger.com/brc
\end{tabular}

Prof. Dr. Sylvia H. Heywang-Köbrunner

Abteilung für Bildgebende und Interventionelle Mammadiagnostik

Klinikum rechts der Isar, TU München

Ismaningerstr. 19, 81675 München, Germany

Tel. +49 89 4140-6731, Fax -6732

E-Mail heywangkoe@lrz.tum.de 


\section{Introduction}

About $50 \%$ of all hereditary breast cancer cases are induced by the breast cancer oncogenes BRCA1 and BRCA2. The remaining cases of suspected inherited origin given by family history might be associated with other known or currently unknown genes.

Compared with the general population female carriers of these deleterious mutations in BRCA1/2 genes are at an increased lifetime risk of both breast and ovarian cancer and are more likely to develop breast cancer at a very young age. Due to the earlier onset of the disease and the faster growth rates of tumors in high-risk patients surveillance needs to start earlier and intervals between the visits need to be shorter. Current recommendations for surveillance of women at increased breast cancer risk or genetic predisposition include: monthly breast self examination starting at age 25 , clinical breast examination and ultrasound every 6 months and annual mammography. The addition of contrast-enhanced magnetic resonance imaging (MRI) is being investigated and discussed (Konsortium familiäre Brust- und Eierstockserkrankungen, $w w w . k r e b s g e s e l l s c h a f t-n r w . d e / d o w n l o a d s / 3 \_$familiaerer_ brustkrebs.pdf).

Prophylactic surgery in BRCA1/2 carriers is an alternative to breast cancer screening but with potential serious physical and psychological consequences. Thus only few women choose this option; the possibilities and limitations of different non invasive imaging screening modalities alone and combined need to be considered.

\section{Imaging Screening Methods}

\section{X-Ray Mammography}

Published data from randomized trials performed in the general population show that mammographic screening may allow a significant reduction of breast cancer mortality [1] After a re-analysis of these extensive data initiated after criticism published by Gøtzsche et al. [2] an official statement issued by the WHO concluded: 'Careful re-assessment of all trials showed that many criticisms were unsubstantiated, remaining deficiencies do not invalidate the results of the trials. Based on the existing data an estimated mortality reduction of $35 \%$ is expected for screening women at age 50-69 every two years' (www.who.int/cancer/detection/breastcancer/en/).

Data concerning mammographic screening in patients aged 40-50 are still limited. Potential reduction of mortality in this age group appears to be lower, up to about $15 \%$ [3]. Since the false-positive rate in this group of women appears to be higher and since the incidence of invasive carcinomas is lower in this age group, the value of screening of the general population in this age group is still critically discussed in Europe.

Female BRCA1/2 mutation carriers may develop breast cancer in $50-90 \%$ of the cases and up to $50 \%$ of the breast can- cers occur before the age of 50 [4]. Prospective studies in women with BRCA1/2 mutation undergoing mammographic surveillance were quite discouraging with a sensitivity of mammography of only 30-40\% [4, 5]. The sensitivity of X-ray mammography is inversely related to breast density [6]. On average breast density is much higher in younger than in postmenopausal women. Therefore the existing data about diagnostic accuracy of X-ray mammography in postmenopausal women cannot be conferred to women at young age $[4,6,7]$. High densitiy at mammography contributes to false negative and false positive mammographic results and an increased number of biopsies. Another reason for the discouraging results in mutation carriers might be the histopathological characteristics associated with the special types of cancers in these women. For example, part of these cancers present with a rounded shape and pushing margins. Cancers with microcalcifications, in contrast, are infrequently associated with hereditary breast cancers in BRCA1 mutation carriers [4, 8].

Concerning an increased risk of radiation-induced breast cancer for mutation carriers by X-ray mammography beams at a very young age is still discussed but further data for a final statement are needed [3] (San Antonio Breast Cancer Meeting 2005).

\section{Ultrasound}

Ultrasound is an excellent complementary method for the assessment of mammographically or clinically detected masses and can add valuable information in mammographically dense tissue. However, for the general population no evidence exists supporting the value of sonographic screening. Sensitivity of ultrasound seems to decrease with lesion size and is minimal for ductal carcinoma in situ (DCIS) [9]. Other problems of sonographic screening might be a high false positive rate among the smaller lesions detected by ultrasound alone. For example, Buchberger et al. reported in a single-center study that an additional 32 cancers could be detected by ultrasound alone in 8,103 patients in their specialized center. However, an additional 330 needle biopsies had to be performed on benign lesions detected by ultrasound alone [10]. Finally, quality assurance and reproducibility of this highly operator-dependent method remain an unsolved issue.

Due to the discouraging results of x-ray mammography ultrasound has been considered and recommended as an additional modality for patients at increased risk by various experts (Konsortium familiäre Brust- und Eierstockserkrankungen). Others do not recommend ultrasound in these patients [11].

Few studies exist comparing mammography, ultrasound and contrast-enhanced MRI. The data concerning ultrasound screening in high-risk populations are quite limited and the above studies show discouraging results with a sensitivity of ultrasound ranging around $30 \%[4,5,12]$. Therefore presently ultrasound is used as an additional tool to screen patients at high risk. To date this recommendation is not evidence-based. 
Table 1. Overview of the sensitivity and specificity of MRI, mammography and ultrasound in women at increased breast cancer risk

\begin{tabular}{|c|c|c|c|c|c|c|c|}
\hline \multirow[t]{2}{*}{ Reference } & \multirow[t]{2}{*}{$\mathrm{n}$} & \multicolumn{2}{|l|}{ MRI } & \multicolumn{2}{|c|}{ Mammography } & \multicolumn{2}{|l|}{ Ultrasound } \\
\hline & & sensitivity, \% & specificity, \% & sensitivity, \% & specificity, \% & sensitivity, \% & specificity, \% \\
\hline Kriege et al. [5] & 1,909 & 71 & 90 & 40 & 95 & & \\
\hline Kuhl et al. [14] & 529 & 91 & 97 & 33 & 96 & 40 & \\
\hline Maribs et al. [13] & 649 & 77 & 81 & 40 & 93 & & \\
\hline Warner et al. [17] & 196 & 100 & 91 & 33 & 99 & 60 & 93 \\
\hline
\end{tabular}

\section{Contrast-Enhanced Magnetic Resonance Imaging}

Contrast-enhanced breast magnetic resonance imaging (MRI) is a very sensitive method capable of detecting additional invasive and in-situ cancers that are occult to state-of-the-art conventional imaging. There are increasing data supporting its value as a complementary imaging tool in patients with increased breast cancer risk. Enhancement of breast lesions after application of intravenous contrast agent reflects tissue changes characteristic for tumor related angiogenesis. However, due to enhancement of various benign changes, MRI may be associated with a significant rate of false positive calls. The aim of the Dutch National Study (MRISK) - a non-randomized prospective mulitcenter study - was to prove the efficacy of MRI compared to mammography in women with familial or genetic breast cancer predisposition. 358 of 1,909 screened women were proven carriers of germ line mutations. The median follow-up time was about 2.9 years. The detected malignancies included 44 invasive cancers, 6 DCIS, 1 lymphoma, and 1 lobular carcinoma in situ. Kriege et al. [5, 12] found the sensitivity of clinical breast examination, mammography, and MRI for detecting invasive breast cancer to be 17.9, 33.3 , and $79.5 \%$, respectively. The specificity was $98.1,95.0$, and $89.8 \%$, respectively. In detail, 18 invasive cancers were detected and 27 were missed by mammography; 22/27 were found by MRI. In this study the sensitivity of mammography was lower than that of MRI except for DCIS. However, the specificity of MRI was lower than that of mammography. The incidence of positive nodes $(21 \%)$ and the tumor size (less than $1 \mathrm{~cm}$ ) in the study group (with MRI) was significant lower than in age-matched control groups without MRI screening. Therefore the authors conclude that MRI contributes to an early cancer detection in women with increased familial breast cancer risk.

The UK MARIBS non-randomized prospective multicenter study provides further important information about MRI screening of women at high familial risk of breast cancer. 649 women at the age of 35-49 years were recruited. 82/649 (13\%) had BRCA1 mutations, 38/649 (6\%) had BRCA2 mutations. Sensitivity of MRI was 77 vs. $40 \%$ for mammography and $94 \%$ for both methods combined. Specifity of MRI was 93 vs. $81 \%$ for mammography and $77 \%$ for both methods combined. The difference in sensitivity comparing both modalities was only significant in BRCA1 mutation carriers, but not in BRCA2 mutation carriers. Neither ultrasound nor CBE were used [13].

The Canadian surveillance study purely investigates BRCA1 or BRCA2 mutation carriers. In this non-randomized prospective single center study Warner et al. examined 236 BRCA1 or BRCA2 mutation carriers and detected 16 invasive cancers and 6 DCIS. 17 (77\%) were detected by MRI vs. $8(36 \%)$ by mammography, 7 (33\%) by ultrasound, and $2(9.1 \%)$ by clinical breast examination (CBE). The sensitivities and specificities were 77 and $95.4 \%$ for MRI, 36 and $99.8 \%$ for mammography, 33 and $96 \%$ for ultrasound, and 9.1 and $99.3 \%$ for $\mathrm{CBE}$, respectively. The overall combined sensitivity of all investigated screening modalities was 95 vs. $45 \%$ for mammography with $\mathrm{CBE}$ and vs. $64 \%$ for mammography, CBE, and ultrasound. MRI detected 9 (75\%) of cancers missed by X-ray mammography and CBE [4].

In a single center study on 529 asymptomatic women at high breast cancer risk 42 breast cancers and 1 interval cancer were detected in 1,542 screening rounds. Kuhl et al. [14] report a sensitivity of $33 \%$ for mammography, of $40 \%$ for ultrasound, of $50 \%$ for mammography and ultrasound and of $97 \%$ for MRI. Reported specificities of mammography and MRI are $97 \%$ and differ from those reported by other authors.

Morris et al. [15] performed a retrospective review of 367 women at high breast cancer risk. In the study group with MRI, biopsy was recommended based on an MRI finding in 64 women (17\%). 14/59 (24\%) invasive cancers occult on mammography and physical examination were detected. The median tumor size was $0.4 \mathrm{~cm}$ (range $0.1-1.2 \mathrm{~cm}$ ). More than half of the MRI-detected cancers were DCIS

Tilanus-Linthorst et al. [8] correlated specific histologic features of cancers in BRCA1/2 carriers and mammographic presentation and accuracy. Significantly more false negatives were found on X-ray mammography in carriers than in controls (62 vs. $29 \%$ ). These observations were independent of tumor size (1.51 vs. 1.75 ) and breast density (high 41 vs. low $53 \%)$. Imaging findings of breast cancers in carriers included significantly fewer spiculated lesions (6 vs. 18) than in controls. Cancers of BRCA1/2 mutation carriers had frequently higher mitotic rates and prominent pushing margins around the tumor (characteristic for medullary carcinoma). The 
prominent pushing margins correlated significantly with a false-negative mammographic interpretation. MRI had 100\% sensitivity and detected 5 cancers, which were occult at clinical breast examination and mammography. An overview of the sensitivity and specificity of the different methods is given in table 1.

\section{Conclusion}

Most of the discussed studies are single center studies, which describe data of small populations and heterogeneous groups. The groups often include only small numbers of proven BRCA1/2 mutation carriers. In spite of the inhomogeneous data, there is increasing evidence that MRI is by far more sensitive than mammography and ultrasound in detecting tumors in women with an inherited susceptibility to breast cancer. The specificity of MRI concerning discrimination between malignant and benign changes varied in the different studies
[5]. The sensitivity of MRI ranges around $80-90 \%$ and is improved by combining mammography, ultrasound, and MRI. Considering these results, MRI appears to be the most promising method. However, its sensitivity is not $95 \%$ and more, as initially suggested.

If breast cancer screening is successful, cancers must be detected at small size and the percentage of distant or nodal metastases should be low. According to the incidence of positive nodes and the tumor size MRI contributes to an early cancer detection in women with increased familial breast cancer risk $[4,5,12,15,16]$.

The utility of MRI is limited by its higher false positive rate, which presently poses the most important challenge for increased use of breast MRI. Therefore further data from prospective and randomized multicenter studies with asymptomatic mutation carriers and long-time follow-up are still needed to investigate the efficacy of MRI as an integral screening modalitiy in the surveillance of women with increased breast cancer susceptibility.

\section{References}

1 Kerlikowske K, Grady D, Rubin SM, Sandrock C, Ernster VL: Efficacy of screening mammography a meta-analysis. JAMA 1995;273:149-154.

$\checkmark 2$ G $\varnothing$ tzsche PC, Olsen O: Is screening for breast cancer with mammography justifiable? Lancet 2000; 355:129-134.

3 Berrington de Gonzales A, Reeves G: Mammographic screening before 50 years in the UK: comparison of the radiation risk with the mortality benefits. Br J Cancer 2005;93:590-596.

4 Warner E, Plewes DB, Hill KA, Causer PA, Zubovits JT, Jong RA, Cutrara MR, DeBoer G, Yaffe MJ, Messner SJ, Meschino WS, Piron CA, Narod SA: Surveillance of BRCA1 and BRCA2 mutation carriers with magnetic resonance imaging, ultrasound, mammography and clinical breast examination. JAMA 2004;292:1317-1325.

5 Kriege M, Brekelmans CTM, Boetes C, Besnard PE, Zonderland HM, Obdeijn IM, Manoliu RA, Kok T, Peterse H, Tilanus-Linthorst MM, Muller SH, Meijer S, Oosterwijk JC, Beex LV, Tollenaar RA, de Koning HJ, Rutgers EJ, Klijn JG; Magnetic Resonance Imaging Screening Study Group: Efficacy of MRI and mammography for breast cancer screening in women with a familial or genetic predisponition. N Engl J Med 2004;351:427-437.
6 Kolb TM, Lichy J, Newhouse JH: Comparison of the performance of screening mammography, physical examination, and breast US and evaluation of factors that influence them: an analysis of 27,825 patient evaluations. Radiology 2002;225:165-175.

7 Brekelmans CTM, Seynaeve C, Bartels CC: Efectiveness of breast cancer surveillance in BRCA $1 / 2$ gene mutation carriers and women with a high familial risk. J Clin Oncol 2001;19:924.

-8 Tilanus-Linthorst M, Verhoog L, Obdeijn IM, Bartels K, Menke-Pluymers MM, Eggermont A, Klijn J, Meuers-Heijboers H, Van der Quast T, Brekelmans CTM: A BRCA 1/2 mutation, high breast density and prominent pushing margins of a tumor independently contribute to a frequent false-negative mammography. Int J Cancer 2002;102:91-95.

9 Potterton AJ, Peakman DH, Young IR: Ultrasound demonstration of small breast cancers detected by mammographic screening. Clin Radiol 1994;49:808.

10 Buchberger W, Niehoff A, Obrist P: Clinically and mammographically occult breast lesions: detection and classification with high-resolution sonography. Semin Ultrasound CT MR 2000;21:325-336.

11 Sauven P on behalf of the Association of Breast Surgery Family History Guidelines Panel: Guidelines for the management of women at increased familial risk of breast cancer. Eur J Cancer 2004; 40:653-665.
12 Kriege M, Brekelmans CTM, Boetes C, Rutgers EJT, Oosterwijk JC, Tollenaar AEM, Manoliu RA, Holland R, de Koening HJ, Klijn JGM: MRI screening for breast cancer in women with familial or genetic predisposition: design of the Dutch National Study (MRISC). Fam Cancer 2001;1:163-168.

13 Maribs Study Group: Screening with magnetic resonance imaging and mammography of a UK population at high familial risk of breast cancer: a prospective multicentre cohort study (MARIBS). Lancet 2005;365:1769-1778.

14 Kuhl CK, Schrading S, Leutner CC, MorakkabatiSpitz N, Wardelmann E, Fimmers R, Kuhn W, Schild HH: Mammography, breast ultrasound and magnetic resonance imaging for surveillance of women at high familial risk for breast cancer. J Clin Oncol 2005;23:8469-8476.

15 Morris EA, Liberman L, Ballon DJ, Robson M, Abramson AF, Heerdt A, Dershaw DD: MRI of occult breast carcinoma in a high risk population. AJR Am J Roentgenol 2003;181:619-626.

16 Robson M, Offit K: Breast MRI for women with hereditary cancer risk. JAMA 2004;292:1368-1370.

17 Warner E, Plewes DB, Shumak RS, Catzavelos GC, Di Prospero LS, Yaffe MJ, Goel V, Ramsay E, Chart PL, Cole DE, Taylor GA, Cutrara M, Samuels TH, Murphy JP, Murphy JM, Narod SA: Comparison of breast magnetic resonance imaging, mammography, and ultrasound for surveillance of women at high risk for hereditary breast cancer. J Clin Oncol 2001;19:3524-3531. 